\title{
Getting to Know a Catena: A Field Exercise for Introductory Soil Science
}

\author{
Ray R. Weil*
}

\begin{abstract}
Hands-on experience is an important part of learning about soils. Examining a catena of soils in the field is an excellent way to help students broaden their knowledge of soil profiles and soil-landscape relationships. This article provides a detailed description of a field exercise that allows students to see and experience the effects of topography on soil morphology using a sideby-side examination of four soil series representing drainage classes from well drained to poorly drained. Attention is drawn to teaching techniques that can maximize the educational benefits of the field exercise.
\end{abstract}

$\mathrm{H}$ ANDS-ON EXPERIENCE is an important part of learning about soils. That is why most introductory soil science courses include a weekly laboratory. Many analyses can be performed on soil material brought into the lab; however, to understand soils as natural bodies in the landscape one must go into their natural habitat. Therefore, the lab portion of introductory soil science courses commonly includes one or more field trips. Examining a catena of soils in the field is an excellent way to help students broaden their knowledge of soil profiles and soil-landscape relationships. Catena is a term first coined in East Africa (Milne, 1935) to describe a grouping of different soils that occur together in the landscape, each soil in a catena differing from the others principally because of the effect of topography on horizontal and vertical water movement and proximity to the water table. In one type of catena, all the soils have formed from the same or related parent materials. This type of catena represents the same concept as the ideal toposequence as used by (Jenny, 1980). While topography is the dominant factor influencing the development of soil properties that differentiate among soil in a catena, it should be recognized that this factor can never be completely isolated from other factors of soil formation (parent material, climate, organisms, and/or time) described by (Jenny, 1941). This article presents a simple but effective approach for studying a catena in a lab class of 15 to 25 students. The laboratory exercise can be conducted in $1.5 \mathrm{~h}$, not including travel time to and from the field site.

\section{LEARNING OBJECTIVES}

After completing this exercise, the student should be able to:

1. Define the term catena.

2. Recognize a catena or toposequence of soils in the field.

3. Make an auger hole and collect soil from a specified depth using a bucket auger.

Department of Natural Resource Sciences and Landscape Architecture, Univ. of Maryland, College Park Md 20742. Received 12 Mar. 2002. *Corresponding author(rw17@umail.umd.edu).

Published in J. Nat. Resour. Life Sci. Educ. 32:1-4 (2003). http://www.JNRLSE.org

(C) American Society of Agronomy

677 S. Segoe Rd., Madison, WI 53711 USA
4. Examine soil during augering to recognize horizon changes.

5. Use soil color, texture, landscape position, and horizon changes to associate an auger hole with a soil description in a soil survey report.

6. Associate soil suborder names with drainage status of several soils in a catena.

7. Determine the drainage class of a soil by the depth of redoximorphic features observed while augering.

8. Explain how soil morphological features might be used to rate a soil as well, moderately, or poorly suited for use as a septic filter field or as a fruit orchard.

\section{CHOOSING THE FIELD SITE}

Selecting an appropriate field site is key to creating a meaningful educational experience in this field exercise. The site should contain a set of soils whose characteristics clearly vary with the topography. In most regions, these characteristics will be largely related to soil drainage. In dry regions, other characteristics such as depth to carbonate layers or soil texture changes may be more important. If possible, it is best to find a site where soils belonging to at least three drainage classes occur side-by-side: a well drained or excessively drained member, a moderately well or somewhat poorly drained member, and a poorly or very poorly drained member. Choosing a site and time of year that will allow students to observe ground water in some of the auger holes will further enhance the educational experience.

The total topographic variation in the catena may be many tens of meters, but often just a few meters difference in elevation will provide major changes in soil profile characteristics. In fact, students have often expressed surprise over the dramatic changes in soil profile properties that can result from very modest changes in surface topography. Before this field experience, many students may have attached little importance to small topographic variations.

In an ideal toposequence, all the soils have been derived from a common parent material. However, the use of a catena in which the parent material changes along the slope should not seriously detract from the teaching value of the exercise. In fact, such a catena may heighten student interest by demonstrating the interaction of two factors of soil formation. However, as this exercise is meant to introduce the topic to the novice, complex or unusual landscapes should be avoided, interesting as they may be to the experienced pedologist.

\section{MATERIALS REQUIRED}

- A bucket type soil auger with a T-handle as long as the deepest soil profile is deep (generally a length of $1.5 \mathrm{~m}$ is sufficient). Some excellent augers come with detachable extension sections in increments of 0.9 to $1.5 \mathrm{~m}$. The auger head should bore a hole between 7 and $10 \mathrm{~cm}$ in diameter. For coarse to medium-textured soils, a closed bucket auger can be used. For fine-textured soils, an opened-sided bucket 
auger may be preferable to allow easier removal of soil material. Although wooden-handled steel bucket augers of the type commonly used to dig post holes are relatively inexpensive, I suggest the use of a high quality alloy auger, which is light weight, strong, and capable of staying sharp. Such augers are available from many forestry, soil science, or farm supply catalogues.

- Munsell Color books (one book for every three or four students)

- $\mathrm{pH}$ dye kit or portable $\mathrm{pH}$ meter with plastic beakers (one kit or meter for every three or four students).

- A large, dull knife or spatula (a butter knife will do in a pinch) to help remove soil from auger.

- A measuring tape at least as long as the auger handle (1.5 $\mathrm{m})$.

- A set of three or four troughs made by sawing a section of $10 \mathrm{~cm}$ (4 inches) diameter polyvinyl chloride (PVC) pipe in half, lengthwise. Each trough should be as long as the deepest profile to be augered $(1.5 \mathrm{~m})$ and should be marked with inches or centimeters using a permanent marker. This will facilitate placing the soil to scale. An optional enhancement for these troughs is to glue a square piece of Plexiglas on either end to hold in the soil material and to prevent the trough from rolling over.

- A form for each student, similar to that shown in Fig. 1, to facilitate taking notes and visualizing the spatial and topographical relationships within the catena.

- A 500-mL squeeze-type water bottle filled with distilled water (one bottle for every three or four students). The distilled water can be used both in $\mathrm{pH}$ determination and to moisten soil for texture by feel.

- A dropper bottle filled with $10 \% \mathrm{HCl}$ (one bottle for every three or four students). The $\mathrm{HCl}$ is necessary only if it is possible that free carbonates will be encountered in the profiles.
- A $10 \times$ hand lens (one lens for every three or four students) for examining small features (soil pores, faint effervescence with applied $\mathrm{HCl}$, small redoximorphic features, or soil animals).

- A plastic dishpan for catching soil from the auger (optional).

- A soils map of the area and soil series descriptions, if available.

\section{PROCEDURE}

Before bringing the class to the site, the instructor should make sure that the profile and drainage features to be studied actually occur in the positions where they are expected. Although unexpected surprises and pedological puzzles are of great value in teaching classes for advanced students and professionals, simplicity is best for beginning soils students who are just being introduced to the soil profile, catena, and toposequence concepts. The site should therefore be chosen so that the pattern of soil properties found in the field agree with what is expected from the principles taught in lecture. It is also advantageous to choose a site for which a soil survey map is available. The pedons to be augered along the drainage catena should be marked with flags labeled with the sequence number $(1,2,3,4)$ and with the soil series name, if that is known.

1. Lead the class to the highest position on the landscape to be investigated. Ask the students to briefly discuss the five soil forming factors as they have affected this landscape. In particular, discuss any changes in elevation and parent material, and the geological causes for these changes. At the first flagged site, ask the students to briefly describe the landscape position (e.g., summit).

2. Then call on one of the students in the class to begin augering (choose a taller student to begin the hole; shorter stu-

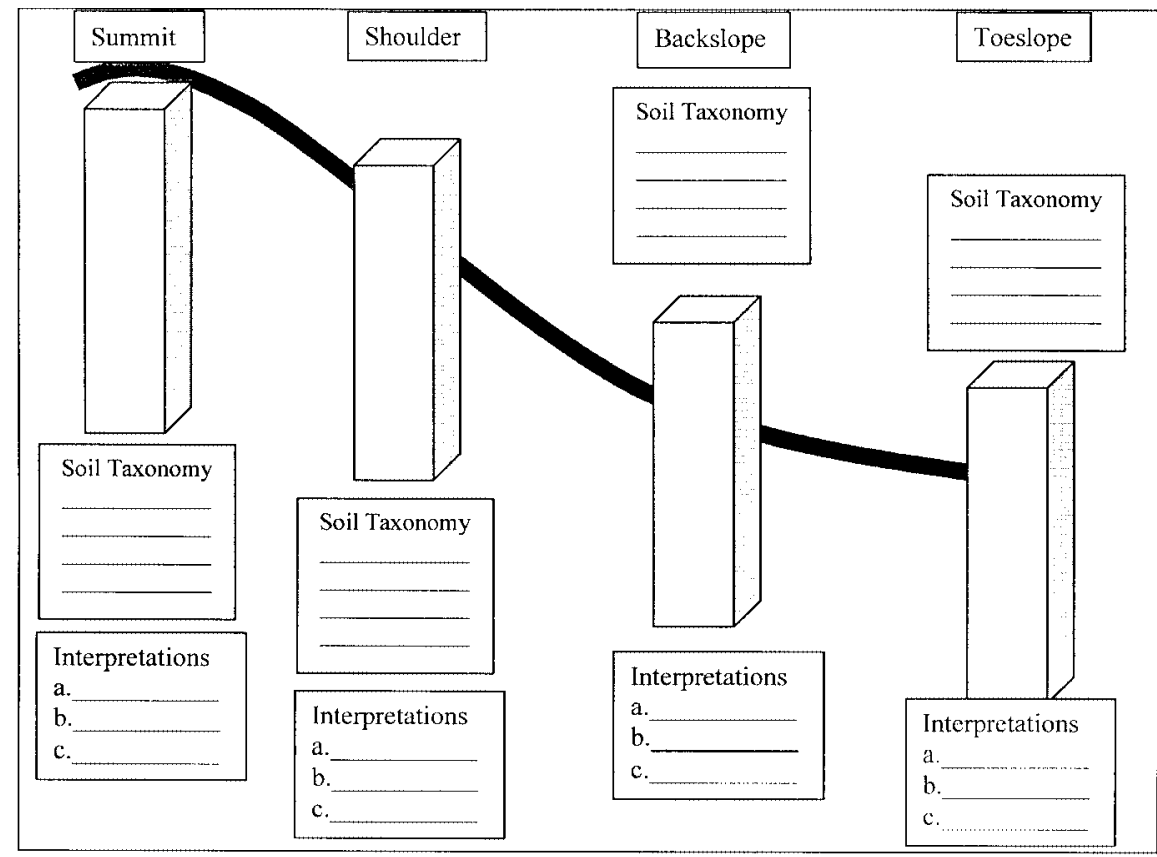

Fig. 1. Diagram of soil profiles in a catena, to be completed in the field. In each profile box, draw in the approximate horizon boundaries and label each horizon identified using standard symbols for genetic horizons (Ap, Bt, etc.). To the right of each profile box, note the textural class (e.g., scl for sandy clay loam) and Munsell color (e.g., 7.5YR3/4). Under Soil Taxonomy, write in the Soil Order, Suborder, Great Group, and Subgroup, if these are known. Under Interpretations, give $(a)$ drainage class, $(b)$ suitability for septic filter field, and $(c)$ suitability for vegetable garden. 
dents may have difficulty reaching the auger handle at this stage). It is important that the student, not the instructor, actually do the augering. Usually, three or four rotations of the auger are required to fill the auger bucket. Although the auger bucket may be 20 to $25 \mathrm{~cm}$ long, it will fill with soil after penetrating only 10 to $12 \mathrm{~cm}$ into soil. In some soils, it is useful to have the class be quiet and listen carefully for changes in the sound of augering as different parent materials are encountered. For example, the sound of the auger cutting through a silt cap is very different from the sound made when the auger enters a sandy or gravelly layer. Explain to the class that such auger noises and changes in the difficulty of augering provide important clues about the profile to the soil scientist. Thus, the class should be able to speculate on the texture of the soil (on the basis of the grinding noise or the difficulty of turning the auger), even before the auger is removed from the hole.

3. Before removing the soil from the auger, the student handling the auger should point the bit end of the auger toward the group and the students should closely inspect the relatively undisturbed soil exposed. The patterns of color, roots, pores and, to some degree, the soil structure, are more clearly visible here than in the soil after being removed from the bucket.

4. Have the student invert the auger so that the T-handle meets the ground at about a 45 degree angle. While one student taps the T-handle gently against the ground causing the soil to fall out of the back of the bucket, a second student should hold a dishpan (or two hands cupped together) under the auger opening to catch as much of the soil as possible as it falls out. A third student can use the steel tape to measure the depth of the hole, and determine the length of the soil increment just collected. The catcher then lays the soil from this increment in the trough so that the soil sample takes up the same length as the increment of profile from which it came.

5. Repeat Steps 2 to 4, rotating duties among the students so that everyone has at least one chance at each task. In this manner, a full-scale profile of the soil will be assembled in the trough (Fig. 2). The class should look for horizon boundaries by observing differences in soil properties and discuss the probable horizon designations. In particular, the features to look for in the well-drained position would be the thickness of the A horizon and the $\mathrm{O}$ horizon (if one is present), and the presence of subsurface horizons, particularly the color of these subsurface horizons. In a well-drained soil, these colors should be fairly bright browns, reds, or yellows (having a high Munsell chroma number). The fact that these bright colors indicate good drainage and aeration should be discussed. The horizon designations and boundaries should be explained and added to the appropriate profile diagram in the form (Fig. 1).

6 . Once the trough is filled with the entire profile, the class should work in teams of three or four students to describe each soil horizon with regard to its colors, texture, structure (as far as possible), presence of carbonates, and $\mathrm{pH}$. Point out to the class that because the auger breaks up the material, the original structure may no longer be intact. The main properties should be noted on the form (Fig. 1) to the right of the appropriate profile diagram.

7. A student should pick up the trough of soil and carry it down the slope to the second flagged position. Here Steps 2 to 6 are repeated. At each flagged site, the soil in the trough is described, paying particular attention to the color chromas in the subsoil, the thickness of the A horizon, and the color hue of the A horizon. The newly filled trough, along with the previous one, is carried to the next site, where Steps 2 to 6 are again repeated. The last soil should have very gray, low chroma colors within $25 \mathrm{~cm}$ of the soil surface.

8 . By the time the last soil is augered, the class will have a collection of three or four soil profiles they can lay side by side (Fig. 3). In most landscapes, a number of soil features can be observed to change systematically from the well drained to the poorly drained positions. These changes are generally more pronounced in humid climates than in drier regions (Birkeland, 1999). Students should be encouraged to see if they can observe the following types of changes in the soils going from the upper to the lower catena members, keeping in mind that different changes may occur in different regions:

a. Increasing A horizon thickness (due to both denser vegetation in the wetter soil and translocation of organic-enriched surface material from upslope by erosion and sedimentation).

b. Darkening of the color of the surface horizon due to the same processes as listed under (a), and slower and less complete decomposition of organic matter in the wetter soils.

c. Change in texture of the surface horizons. (For example, in deep loess, erosion may preferentially move the silt and clay fractions downhill, leaving sandier material on the summit and shoulder and deposits of silt and clay in

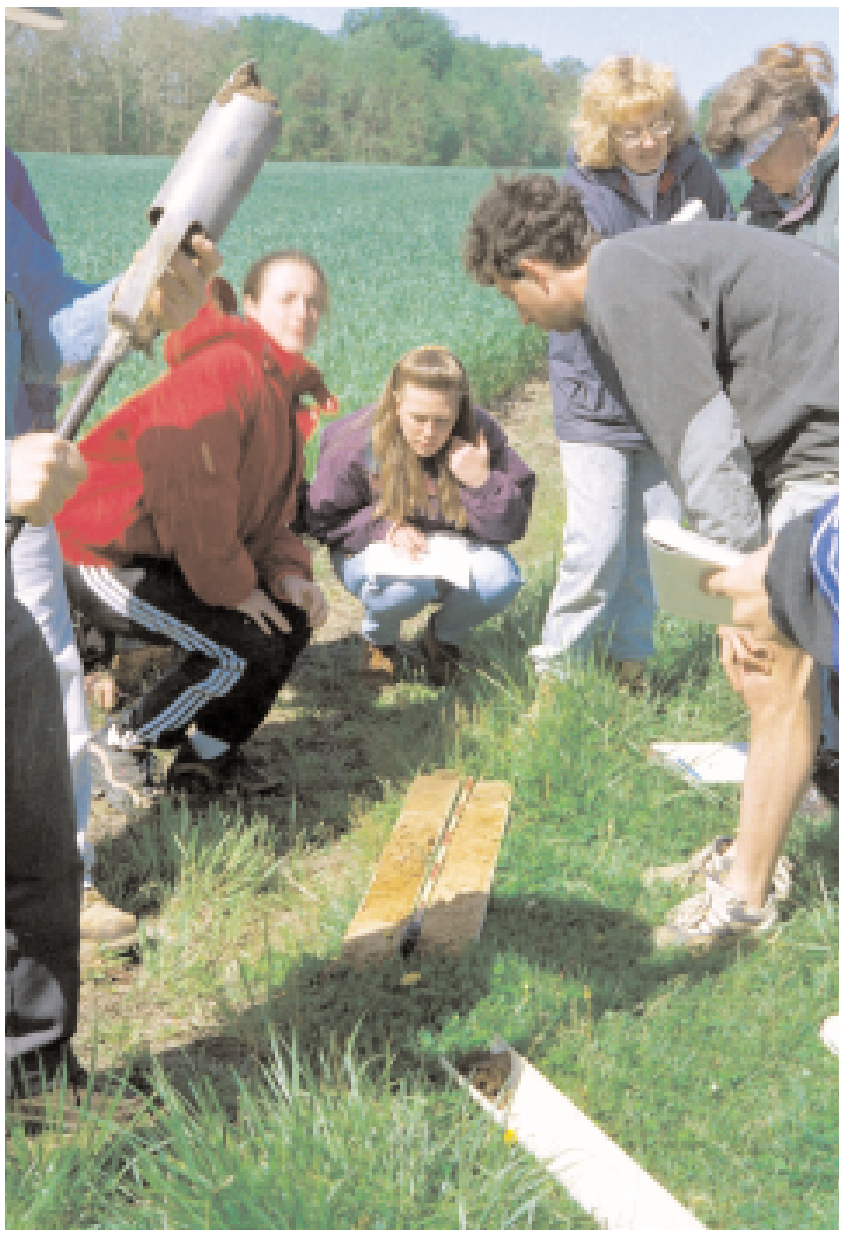

Fig. 2. Students place augered soil in a trough and examine the resulting profile under the supervision of a graduate teaching assistant. 


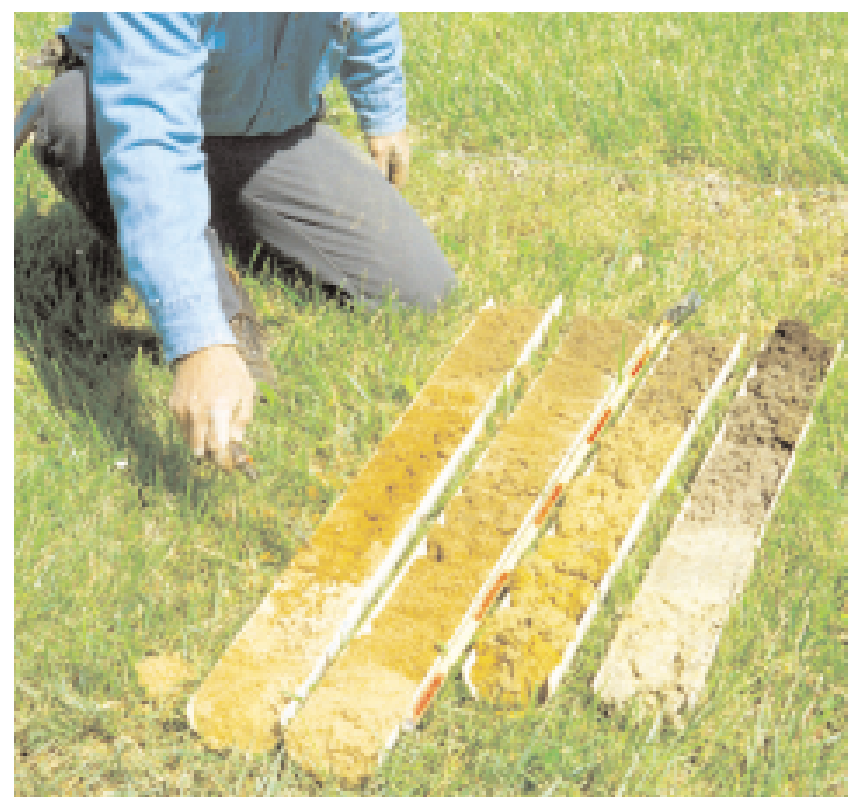

Fig. 3. Four soil troughs lie side by side for comparison of soil profiles in a catena.

the lower positions. On the other hand, in catenas with well developed argillic horizons, the upper catena members may have the finer-textured surfaces because erosion has removed most of their coarse-textured $\mathrm{A}$ and $\mathrm{E}$ horizons, exposing the clayey material from the B horizons.)

d. Decreasing chroma values in the subsurface horizons and increasing frequency of mottles (iron depletion spots) or other redoximorphic features in these horizons.

e. Occurrence of redoximorphic features closer to the soil surface. USDA-NRSC (1998) is a good reference for particular redoximorphic features common in different regions.

f. Change in the odor of the soil, with an aromatic earthy smell in the well-drained soil and a more putrid (sometimes sulfide) odor in the most poorly drained member, especially during the wet season.

9. If possible, the lowest elevation site should be chosen so the water table occurs within $2 \mathrm{~m}$ or less of the soil surface. If this is the case, it is worth trying to reach the ground water level. Students should observe that the soil increments are nearly saturated when the auger begins to sample the capillary fringe above the water table. While the students handle the saturated material from below the water table, the instructor should point out such features as the semi fluid state of the saturated soils and the cool temperature of the water, which, if the water table is more than 1 to $2 \mathrm{~m}$ deep, will approximate the mean annual temperature for the region. The students should look down the hole, see the reflection of the sky on the free water surface, and then use the steel tape to determine the depth of the water table immediately after augering. Students should then measure the depth to the water table again after about $10 \mathrm{~min}$ have passed. The rate of rise in the ground water level gives some indication of the recharge rate and the soil permeability. Many students reported this exercise was their first actual experience seeing and feeling ground water and saturated soil.
10. Finally, once all the lessons are learned, it is important for the students to go back to each auger hole with the appropriate trough of soil and pour the soil, bottom horizon first, back into the hole. Students can also use any soil remaining around the hole to fill the holes and prevent a hazard to people or livestock that might be walking through the area (horses are especially susceptible to breaking a leg in an auger hole). The instructor should explain that filling of the holes is also important to protect ground water from surface contaminants that might wash in.

\section{CONCLUSION}

The key feature of this exercise is the juxtaposition of profiles from different landscape positions, as accomplished by actually picking up the profile models and laying them sideby-side (Fig. 3). Students have indicated that seeing the soils side-by-side leaves a lasting impression as to (i) the dramatic differences in soil properties that can occur with small differences in topography and in a relatively small area, and (ii) the systematic effects of the topographic soil forming factor (possibly, as modified by other soil forming factors).

This exercise will be of greatest educational value if students have already been exposed to the concepts of soil formation, particularly the influence of topography and hydrology (such as introduced in Brady and Weil (2002, p. 54-72 and 290-293); and if the exercise follows a field trip in which students examine one or more soil profiles in soil pits. Ideally, students will have seen a pit profile of at least one of the soil series included in the study catena. The previous experience in the soil pit will help them relate the pieces of soil material that the auger brings up to the appearance of the soil in place. At each landscape position, every student should have a turn at the soil auger and every student should determine the texture, $\mathrm{pH}$, and color for at least one of the horizons. Therefore, working in teams, each individual has a chance to really get the feel of the soils. This field exercise will go more smoothly and be more meaningful to students if it is preceded by an exercise in which students learn to determine texture by feel, use the Munsell color book, and determine $\mathrm{pH}$ (such as Exercises 4 and 17 in Weil, 1998). If these skills were learned for the first time during the catena field exercise, the need for instruction and practice of these skills would considerably lengthen the time required to complete the exercise, and would detract from the focus on landscape-soil relationships.

\section{REFERENCES}

Birkeland, P.W. 1999. Soils and geomorphology. 3rd ed. Oxford Univ. Press, New York.

Brady, N.C., and R.R. Weil. 2002. The nature and properties of soils. 13th ed. Prentice-Hall, Upper Saddle River, NJ.

Jenny, H. 1941. Factors of soil formation: A system of quantitative pedology. McGraw Hill, New York.

Jenny, H. 1980. The soil resource, origin and behavior. Springer, New York. Milne, G. 1935. Some suggested units of classification and mapping for East African soils. Soil Res. 4:183-198.

U.S. Department of Agriculture-Natural Resources Conservation Service. 1998. Field indicators of hydric soils in the United States. Version 4.0. USDA-NRCS, Fort Worth, TX.

Weil, R.R. 1998. Laboratory manual for introductory soils. 6th ed. Kendall/Hunt, Dubuque, IA. 